\title{
Emotional arousal and enhanced amygdala activity: New evidence for the old perseveration-consolidation hypothesis
}

\author{
James L. McGaugh \\ Center for the Neurobiology of Learning and Memory, and Department of Neurobiology and Behavior, \\ University of California, Irvine, California 92697-3800, USA
}

Just a little over a century has passed since Müller and Pilzecker (1900) proposed the "perseveration-consolidation" hypothesis suggesting that neural activity initiated by newly learned information perseverates for a while and that such perseveration is critical for consolidating memory. Although memory consolidation is currently the focus of considerable research investigating the molecular mechanisms responsible for converting new memories into lasting memories and the brain regions essential for such conversion, "perseveration" has been dropped from the hyphenated hypothesis and has not remained an explicit focus of research and theory concerning memory consolidation (McGaugh 1999, 2000).

The essential experimental evidence supporting the memory consolidation hypothesis is that the memoryinfluencing effectiveness (i.e., impairment or enhancement) of treatments administered after training decreases as the training-treatment interval is increased. Such findings do not require an assumption that the treatments act by altering perseverating neural activity, as many kinds of neural alterations might be (and probably are) responsible for time-dependent effects of post-training treatments. Although it is now generally accepted that memories are formed by the action of processes occurring over time after learning, it is also generally assumed that such processes may involve many sequential cellular events as well as sequential functioning of different brain systems (McClelland et al. 1995; Squire and Alvarez 1995; Izquierdo et al. 2004).

The findings of the study by Pelletier et al. (2005) in this issue of Learning \& Memory, provide compelling evidence suggesting that it may now be appropriate to restore "perseveration-" to the consolidation hypothesis. Using extracellular multiple microelectrode arrays, Pelletier and colleagues recorded the activity of neurons in the basolateral amygdala (BLA) of cats before and after a mild footshock administered for inhibitory avoidance training. The firing rate of the neurons, as well as the synchrony of the firing, increased significantly after the footshock, peaked at over half an hour later and did not return to baseline until over $2 \mathrm{~h}$ after the footshock. This general pattern of increased postfootshock activity was observed in approximately half of the BLA neurons that were recorded and was more prominent during slow-wave sleep than during wakefulness. Interestingly, the activity of some neurons peaked shortly after the footshock, whereas the activity of most cells peaked $\sim 40$ min after the footshock. As Pelletier et al. (2005) note, this evidence of long-lasting (i.e., perseverating) increased firing of BLA neurons induced by footshock training fits well with the extensive evidence that the BLA is critically involved in modulating the consolidation of

E-mail jlmcgaug@uci.edu; fax (949) 824-2952.

Article and publication are at http://www.learnmem.org/cgi/doi/10.1101/ Im.93405. emotionally arousing experiences (McGaugh 1990, 2004; Paré 2003).

It is well established that adrenal stress hormones released by emotionally arousing experiences modulate memory consolidation. Post-training administration of epinephrine or corticosterone produces dose-dependent and time-dependent enhancement of retention of a wide variety of training tasks, including inhibitory avoidance (McGaugh and Roozendaal 2002). These adrenergic and glucocorticoid treatments are ineffective in influencing memory when administered several hours after training. Importantly, in relation to the findings of Pelletier et al. (2005), adrenergic and glucocorticoid effects on memory consolidation are mediated by actions involving the BLA. Selective lesions of the BLA or adrenoceptor antagonists infused into the BLA block the memory-modulating effects of systemically administered adrenal stress hormones, and infusions of adrenoceptor agonists (e.g., norepinephrine) and glucocorticoid receptor agonists administered selectively into the BLA immediately after training produce dose-dependent enhancement of memory consolidation (McGaugh and Roozendaal 2002). Systemically administered adrenal stress hormones also increase the release of norepinephrine (NE) in the amygdala (Williams et al. 1998; McIntyre et al. 2004). Additionally, in rats given inhibitory avoidance training, NE levels in the amygdala increased immediately after the training and did not decline to baseline level for several hours. NE levels assessed within 90 min after training correlated highly with subsequent retention performance (McIntyre et al. 2002). Such findings support the general hypothesis that the adrenal stress hormones released by training-induced emotional arousal enhance memory consolidation by increasing both the amount and duration of noradrenergic activation within the amygdala (McGaugh and Roozendaal 2002).

As Pelletier et al. (2005) note, the duration of increased BLA electrophysiological activity seen after inhibitory avoidance training fits well with the evidence from experiments investigating the effects of stress hormones and training-induced emotional arousal on NE release and memory (Paré 2003). Thus, it is tempting to suggest that the emotional arousal-induced increase in BLA noradrenergic activity and neuronal activity may be causally related. The increase in NE activity may directly affect neuronal firing of GABAergic local-circuit cells as well as projection cells within the BLA. Although it is also possible that the BLA neuronal firing might increase NE release by feedback to presynaptic adrenergic receptors or to brain stem noradrenergic sources (locus coeruleus and/or nucleus of the solitary tract), this seems unlikely, because NE levels increase quickly and peak within 15$30 \mathrm{~min}$ after inhibitory avoidance training, whereas the peak of the increase in BLA firing reported by Pelletier et al. (2005) occurred later than that in most cells recorded. However, as the activity of a minority of neurons peaked within seconds after the footshock training, the possibility that such early neuronal ac- 
tivity might affect NE release cannot be excluded. This issue might be investigated by infusing lidocaine into the BLA after training. As prior studies have reported that reversible inactivation of the BLA with lidocaine or tetradotoxin either immediately or within several hours after training impairs memory (Bucherelli et al. 1992; Parent and McGaugh 1994), it would be of interest to know whether such lidocaine infusions alter NE release within the amygdala.

As noted above, there is considerable evidence that NE activity within the BLA plays an essential role in mediating the influence of emotional arousal and stress hormones on memory consolidation. Does the increase in BLA activity induced by training also play a critical role? Although Pelletier et al. (2005) did not investigate this question, they interpreted their findings as suggesting that the increase in post-training BLA activity may enhance memory consolidation by influencing neuroplasticity in other brain regions. Extensive evidence from pharmacological studies indicates that the BLA modulates memory consolidation via its projections to other brain regions (McGaugh 2002). There is also extensive evidence that the BLA influences neuroplasticity in other brain regions. Selective lesions of the BLA or infusions of a $\beta$-adrenoceptor into the BLA block the induction of long-term potentiation (LTP) in the dentate gyrus (Ikegaya et al. 1994, 1997; Akirav and RichterLevin 1999; Frey et al. 2001). Lesions of the amygdala also block stress-induced influences on hippocampal LTP (Kim et al. 2001). Electrical stimulation of the BLA enhances LTP in the cortex and dentate gyrus of the hippocampus (Ikegaya et al. 1995; Akirav and Richter-Levin 2002; Dringenberg et al. 2004; Nakao et al. 2004). Previous studies have also reported that posttraining electrical stimulation of the amygdala can modulate memory consolidation and that such effects are mediated by projections to other brain regions (Gold et al. 1975; Liang and McGaugh 1983).

Although other investigators have observed effects of aversive training (using footshock) on the firing of amygdala neurons after training (Quirk et al. 1995; Maren 2000) and during retention testing (Chang et al. 2005), the study by Pelletier et al. (2005) is the first to investigate the sustained time course and increased synchrony of the increased BLA activity following the emotional arousal induced by inhibitory avoidance training. Evidence from human brain imaging studies suggests that amygdala activity during encoding of emotionally arousing material influences long-term memory via influences involving hippocampal/ parahippocampal regions (Cahill et al. 1996; Dolcos et al. 2004; Kilpatrick and Cahill 2003), but such studies have not as yet investigated the involvement of amygdala activity occurring after encoding.

Thus, the proposal by Pelletier et al. (2005) that the arousalinduced increases in BLA neuronal activity may promote plasticity in other brain regions is generally well supported by both electrophysiological and behavioral evidence. The evidence is also consistent with their hypothesis that, "... the memorymodulating role of the BLA would not depend on the specific activation of particular groups of BLA neurons, but on the activity patterns taking place in BLA projection sites when emotional arousal occurred." An important implication of this hypothesis is that training must also induce neuronal processes in other brain regions that continue for several hours after training and remain susceptible to sustained BLA influence. Although this implication is supported by the findings of many studies reporting timedependent effects of post-training treatments affecting the BLA, the findings reported here by Pelletier et al. (2005) are the first to provide evidence that emotionally arousing training induces perseverating neural activity in the BLA. These novel and important findings suggest that it may be appropriate, perhaps even neces- sary, to re-hyphenate Müller and Pilzecker's (1900) "persevervation-consolidation" hypothesis.

\section{References}

Akirav, I. and Richter-Levin, G. 1999. Biphasic modulation of hippocampal plasticity by behavioral stress and basolateral amygdala stimulation in the rat. J. Neurosci. 19: 10530-10535.

Akirav, I. and Richter-Levin, G. 2002. Mechanisms of amygdala modulation of hippocampal plasticity. J. Neurosci. 22: 9912-9921.

Bucherelli, C., Tassoni, G., and Bures, J. 1992. Time-dependent disruption of passive avoidance acquisition by post-training intra-amygdala injection of tetrodotoxin in rats. Neurosci. Lett. 140: $231-234$.

Cahill, L., Haier, R.J., Fallon, J., Alkire, M., Tang, C., Keator, D., Wu, J., and McGaugh, J.L. 1996. Amygdala activity at encoding correlated with long-term, free recall of emotional information. Proc. Natl. Acad. Sci. 93: 8016-8021.

Chang, C-H., Liang, K-C., and Yen, C-T. 2005. Inhibitory avoidance learning altered ensemble activity of amygdaloid neurons in rats. Eur. J. Neurosci. 21: 210-218.

Dolcos, F., Graham, R., LaBar, K., and Cabeza, R. 2004. Interaction between the amygdala and the medial temporal lobe memory system predicts better memory for emotional events. Neuron 42: 855-863.

Dringenberg, H.C., Kuo, M-C., and Tomaszek, S. 2004. Stabilization of thalamo-cortical long-term potentiation by the amygdala: Cholinergic and transcription-dependent mechanisms. Eur. J. Neurosci. 20: 557-565.

Frey, S., Bergado-Rosado, J., Seidenbecher, T., Paper, H.C., and Frey, J.U. 2001. Reinforcement of early long-term potentiation (early-LTP) in dentate gyrus by stimulation of the basolateral amygdala: Heterosynaptic induction mechanisms of late-LTP. J. Neurosci. 21: $3697-3703$.

Gold, P.E., Hankins, L., Edwards, R.M., Chester, J., and McGaugh, J.L. 1975. Memory interference and facilitation with posttrial amygdala stimulation: Effect on memory varies with footshock level. Brain Res. 86: $509-513$.

Ikegaya, Y., Saito, H., and Abe, K. 1994. Attenuated hippocampal long-term potentiation in basolateral amygdala-lesioned rats. Brain Res. 656: 157-164.

Ikegaya, Y., Saito, H., and Abe, K. 1995. Requirement of basolateral amygdala neuron activity for the induction of long-term potentiation in the dentate gyrus in vivo. Brain Res. 671: 351-354.

Ikegaya, Y., Saito, H., Abe, K., and Nakanishi, K. 1997. Amygdala $\beta$-noradrenergic influence on hippocampal long-term potentiation in vivo. NeuroReport 8: $3143-3146$.

Izquierdo, I., Cammarota, M., Medina, J.H., and Bevilaqua, L.R. 2004. Pharmacological findings on the biochemical bases of memory processes: A general view. Neural Plast. 11: 159-189.

Kilpatrick, L. and Cahill, L. 2003. Amygdala modulation of parahippocampal and frontal regions during emotionally influenced memory storage. Neuroimage 20: 2091-2099.

Kim, J.J., Lee, H.J., Han, J.-S., and Packard, M.G. 2001. Amygdala is critical for stress-induced modulation of hippocampal long-term potentiation and learning. I. Neurosci. 21: 5222-5228.

Liang, K.C. and McGaugh, J.L. 1983. Lesions of the stria terminalis attenuate the amnestic effect of amygdaloid stimulation on avoidance responses. Brain Res. 274: 309-318.

Maren, S. 2000. Auditory fear conditioning increases CS-elicited spike firing in lateral amygdala neurons even after extensive overtraining. Eur. J. Neurosci. 12: 4047-4054.

McClelland, J.L., McNaughton, B.L., and O'Reilly, R.C. 1995. Why there are complementary learning systems in the hippocampus and neocortex: Insights from the successes and failures of connectionist models of learning and memory. Psychol. Rev. 102: 419-457.

McGaugh, J.L. 1990. Significance and remembrance: The role of neuromodulatory systems. Psychol. Sci. 1: 15-25.

1999. The perseveration-consolidation hypothesis: Müller and Pilzecker, 1900. Brain Res. Bull. 50: 445-446.

. 2000. Memory-A century of consolidation. Science 287: 248-251.

2002. Memory consolidation and the amygdala: A systems perspective. TINS 25: $456-461$.

. 2004. The amygdala modulates the consolidation of memories of emotionally arousing experiences. Annu. Rev. Neurosci. 27: 1-28.

McGaugh, J.L. and Roozendaal, B. 2002. Role of adrenal stress hormones in forming lasting memories in the brain. Curr. Opin. Neurobiol. 12: $205-210$.

McIntyre, C.K., Hatfield, T., and McGaugh, J.L. 2002. Amygdala norepinephrine levels after training predict inhibitory avoidance retention performance in rats. Eur. J. Neurosci. 16: 1223-1226.

McIntyre, C., Roozendaal, B., and McGaugh, J.L. 2004. Glucocorticoid 
Amygdala neuronal activity and memory consolidation

treatment enchances training-induced norepinephrine release in the amygdala. Soc. Neurosci. (abstract \#772.12).

Müller, G.E. and Pilzecker, A. 1900. Experimentalle beitrage zur lehre vom gedächtnis. Zeitschrift fuer Psychologie 1: 1-288.

Nakao, K., Matsuyama, K., Matsuki, N., and Ikegaya, Y. 2004. Amygdala stimulation modulates hippocampal synaptic plasticity. Proc. Natl. Acad. Sci. 101: 14270-14275.

Paré, D. 2003. Role of the basolateral amygdala in memory consolidation. Prog. Neurobiol. 70: 409-420.

Parent, M.B. and McGaugh, J.L. 1994. Posttraining infusion of lidocaine into the amygdala basolateral complex impairs retention of inhibitory avoidance training. Brain Res. 661: 97-103.

Pelletier, J.G., Likhtik, E., Filali, M., and Paré D. 2005. Lasting increases in basolateral amygdala activity after emotional arousal: Implications for facilitated consolidation of emotional memories. Learn. Mem. (this issue).

Quirk, G.J., Repa, C., and LeDoux, J.E. 1995. Fear conditioning enhances short-latency auditory responses of lateral amygdala neurons: Parallel recordings in the freely behaving rat. Neuron 15: 1029-1039.

Squire, L.R. and Alvarez, P. 1995. Retrograde amnesia and memory consolidation: A neurobiological perspective. Curr. Opin. Neurobiol. 5: $169-177$.

Williams, C.L., Men, D., Clayton, E.C., and Gold, P.E. 1998. Norepinephrine release in the amygdala after systemic injection of epinephrine or escapable footshock: Contribution of the nucleus of the solitary tract. Behav. Neurosci. 112: 1414-1422. 


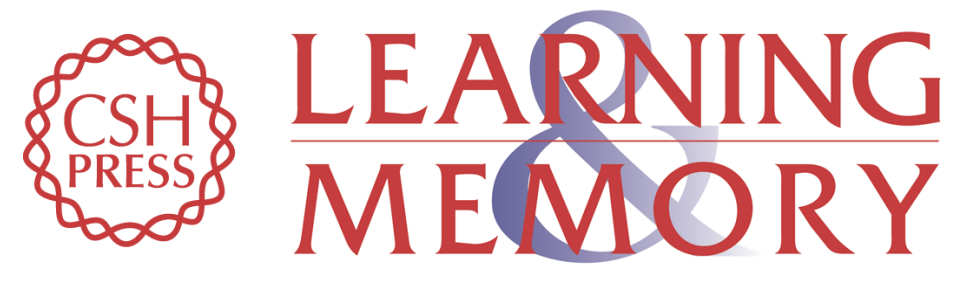

\section{Emotional arousal and enhanced amygdala activity: New evidence for the old perseveration-consolidation hypothesis}

James L. McGaugh

Learn. Mem. 2005, 12:

Access the most recent version at doi:10.1101//m.93405

References This article cites 32 articles, 7 of which can be accessed free at: http://learnmem.cshlp.org/content/12/2/77.full.html\#ref-list-1

License

Email Alerting Receive free email alerts when new articles cite this article - sign up in the box at the Service top right corner of the article or click here. 